\title{
Resource availability, matrix quality, microclimate, and spatial pattern as predictors of patch use by the Karner blue butterfly
}

\author{
Ralph Grundel*, Noel B. Pavlovic \\ US Geological Survey, 1100 North Mineral Springs Road, Porter, IN 46304, United States
}

\section{A R T I C L E I N F O}

\section{Article history:}

Received 6 March 2006

Received in revised form

29 September 2006

Accepted 3 October 2006

Available online 15 November 2006

\section{Keywords:}

Endangered species

Hierarchical partitioning

Insect distribution

Lupinus perennis

Lycaeides melissa samuelis

Oak savanna

\begin{abstract}
A B S T R A C T
Determination of which aspects of habitat quality and habitat spatial arrangement best account for variation in a species' distribution can guide management for organisms such as the Karner blue butterfly (Lycaeides melissa samuelis), a federally endangered subspecies inhabiting savannas of Midwest and Eastern United States. We examined the extent to which three sets of predictors, (1) larval host plant (Lupinus perennis, wild lupine) availability, (2) characteristics of the matrix surrounding host plant patches, and (3) factors affecting a patch's thermal environment, accounted for variation in lupine patch use by Karner blues at Indiana Dunes National Lakeshore, Indiana and Fort McCoy, Wisconsin, USA. Each predictor set accounted for 7-13\% of variation in patch occupancy by Karner blues at both sites and in larval feeding activity among patches at Indiana Dunes. Patch area, an indicator of host plant availability, was an exception, accounting for $30 \%$ of variation in patch occupancy at Indiana Dunes. Spatially structured patterns of patch use across the landscape accounted for $9-16 \%$ of variation in patch use and explained more variation in larval feeding activity than did spatial autocorrelation between neighboring patches. Because of this broader spatial trend across sites, a given management action may be more effective in promoting patch use in some portions of the landscape than in others. Spatial trend, resource availability, matrix quality, and microclimate, in general, accounted for similar amounts of variation in patch use and each should be incorporated into habitat management planning for the Karner blue butterfly.
\end{abstract}

Published by Elsevier Ltd.

\section{Introduction}

Two paradigms dominate current explanations of local insect distribution (Gripenberg and Roslin, 2005). The first paradigm suggests that insect distribution is mainly determined by differences among sites in quality and quantity of resources needed by adults and larvae and by differences in environmental conditions within the site (Dennis et al., 2006). For herbivorous insects, resource differences among sites might include variations in chemical composition and abundance of host plants associated with local gradients, such as gradients of solar insolation or shading (Grundel et al., 1998a). Such local environmental conditions can also produce microclimatic differences among sites. Microclimatic differences can affect insect thermoregulation, rates of insect development, and synchrony between development of the host plant and development of the insect (Weiss et al., 1988; Fleishman et al., 2000; Hellmann, 2002). The second prevailing paradigm emphasizes how habitat arrangement across a landscape affects patterns of site occupancy by an insect (Harrison et al.,

* Corresponding author: Tel.: +1 219926 8336; fax: +1 2199295792.

E-mail addresses: rgrundel@usgs.gov (R. Grundel), npavlovic@usgs.gov (N.B. Pavlovic). 0006-3207/\$ - see front matter Published by Elsevier Ltd.

doi:10.1016/j.biocon.2006.10.003 
1988; Hanski et al., 1996; Doak, 2000; Gripenberg and Roslin, 2005). In this paradigm, an insect's extinction within, and recolonization of, habitat patches largely determines patch use patterns. Recolonization, in turn, is affected by patch isolation or connectivity of patches to one another.

The performance of these two paradigms in predicting patch use has been examined for several insect species, mainly butterflies, and outcomes have included situations in which: (a) habitat quality, area, and isolation or connectivity all affected habitat use patterns of an insect population (Dennis and Eales, 1997; Anthes et al., 2003; James et al., 2003; Sawchik et al., 2003), (b) characteristics of habitat quality, such as larval host plant cover (Krauss et al., 2004), were significant predictors of adult butterfly abundance while isolation was not, (c) habitat quality and isolation were significantly related to butterfly patch occupancy but patch size was not (Thomas et al., 2001), (d) macro-habitat characteristics, such as sheltering of host plants, and isolation, but not host plant quality, were significant predictors of butterfly patch occupancy (Gutiérrez et al., 1999), (e) area and isolation were relatively poor predictors of butterfly patch occupancy but habitat quality was a significant predictor (Fleishman et al., 2002), (f) spatial pattern and patch quality interacted in that spatial segregation of adult food resources was the main determinant of distribution of females and, subsequently, of larvae (Fred et al., 2006), and (g) spatial arrangement of patches dominated over host plant or habitat quality in ability to predict insect distribution (Moilanen and Hanski, 1998; Gripenberg and Roslin, 2005). The balance between connectivity, or other spatial effects, and habitat composition and quality as primary determinants of distribution patterns may be affected by how an insect's dispersal ability compares to the scale of variation in habitat composition (Gripenberg and Roslin, 2005; van Nouhuys, 2005). Also, differences in how isolation or connectivity are measured (Moilanen and Nieminen, 2002; Winfree et al., 2005) and differences in methods for analyzing importance of different predictors (Heikkinen et al., 2005) can affect conclusions reached concerning the relative importance of spatial effects versus habitat composition.

Understanding tradeoffs between habitat spatial configuration and habitat quality and quantity in the determination of insect distribution can guide insect conservation management decisions (Schultz and Crone, 2005). For example, spatial configurations of habitat patches can affect population or metapopulation viability (Hanski and Meyke, 2005; Baguette and Schtickzelle, 2006) and insect density can be related to resource quantity and habitat quality (Krauss et al., 2004). Therefore, characterizing the nature of tradeoffs between habitat spatial configuration and habitat composition is important for effective management of the Karner blue butterfly (Lycaeides melissa samuelis Nabokov), a US federally endangered subspecies that has been extirpated from many locations of historic occurrence in the US and from all sites in Canada (US Fish and Wildlife Service, 2003). L. melissa samuelis is a bivoltine, monophagous subspecies, whose larvae feed on leaves of wild lupine, Lupinus perennis L. The heterogeneous canopy cover of the oak savannas and pine barrens inhabited by the Karner blue produces many lupine patches, with lupine often being less abundant in areas of heaviest canopy cover (Grundel et al., 1998b). Management therefore often emphasizes maintenance of open areas to promote growth of lupine and to improve connection among lupine patches. However, the presence of a range of shade conditions, or thermal environments, is advantageous to the Karner blue (Grundel et al., 1998a,b; Lane and Andow, 2003). This advantage may arise, in part, because most sites inhabited by Karner blues occur on sandy soils. On such welldrained soils, shading and topographic position of lupine patches can affect both water availability to plants, a factor known to affect Karner blue larval growth rate (Grundel et al., 1998a), and the thermal environment, which can affect larval development rates and adult thermoregulation (Weiss et al., 1988; Dennis and Sparks, 2006).

In assessing tradeoffs among quality and quantity components of habitat composition on Karner blue distribution, and between habitat spatial arrangement and habitat composition, habitat composition can be examined from several perspectives. Here we ask, how well the following three groups of factors related to habitat composition, accounted for variation in patch use by the Karner blue: (1) resource availability (Heikkinen et al., 2005), including abundance of host plants, (2) quality of the matrix surrounding a patch (Dennis et al., 2006), indicated, in part, by occurrence of occupied and unoccupied patches in the surrounding landscape, and (3) factors affecting microclimate, including solar insolation levels, patch elevation, and patch shading. In addition, we ask whether the relationships of habitat composition to patch use vary if we define patch use in different ways. To what extent do location of patches within the landscape, and location of patches relative to each other, affect patterns of patch use? Answers to these questions can help set habitat management priorities for this endangered species.

\section{Methods}

\subsection{Study area}

The distribution of Karner blue butterflies was examined at Indiana Dunes National Lakeshore, a 5400 ha unit of the US National Park Service, situated along the southern shore of Lake Michigan near Gary, Indiana, USA $\left(41^{\circ} 37^{\prime} \mathrm{N}, 87^{\circ} 15^{\prime} \mathrm{W}\right)$, and at Fort McCoy, a 24,106 ha military training area in southwestern Wisconsin, USA $\left(44^{\circ} 06^{\prime} \mathrm{N}, 90^{\circ} 37^{\prime} \mathrm{W}\right)$ (Smith et al., 2002). At Indiana Dunes, study habitats were a series of sand dunes and valleys covered by black oak (Quercus velutina Lamarck) savannas and woodlands (Cowles, 1899). Lupine patches were often separated from each other by wetlands and areas of high canopy cover. About half of Fort McCoy was covered by oak-(Q. alba L., Q. ellipsoidalis E.J. Hill, Q. rubra L. and Q. velutina) dominated habitats and about $15 \%$ by jack pine-(Pinus banksiana Lamb.) dominated habitats.

\subsection{Patch characteristics}

Patches were defined by presence of wild lupine, with gaps in coverage up to $10 \mathrm{~m}$ allowed. Two networks of patches (75 and $350 \mathrm{ha}$ ), containing 81 patches, were examined at Indiana Dunes (Fig. 1) in 1994. During mark-release-recapture studies, Karner blue adults moved between patches within each net- 


\section{Indiana Dunes}
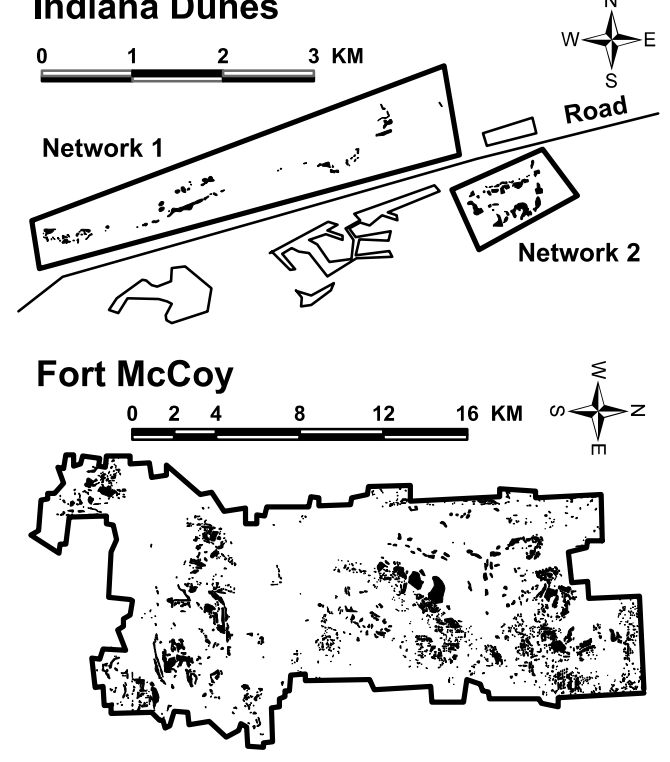

Fig. 1 - Lupine patches at Indiana Dunes National Lakeshore (top) and Fort McCoy, Wisconsin (bottom). At Indiana Dunes, additional, unexamined patch networks are outlined. For Fort McCoy, border represents installation boundary and the extent of this study.

work but not between networks (Knutson et al., 1999). Across Fort McCoy, 2073 patches were delineated in 1993-1994. After combining patches that were separated by $<10 \mathrm{~m}, 1589$ lupine patches remained (Fig. 1).

Patches at Fort McCoy were visited, in 1993 or 1994, during either the first or the second brood to determine whether any adults were present. If adults were not observed, patches were later examined for larval signs, between the first and second broods. If no adults, larvae, or larval signs were observed, the patch was considered unoccupied (Patch Occupancy $=0)(n=162)$. At Indiana Dunes, we examined lupines throughout a patch for larval feeding damage during late July and early August, near the end of the final yearly larval feeding cycle. A patch was occupied (Patch Occupancy $=1)(n=70)$ if any evidence of Karner blue larval feeding damage was noted. To contrast occupancy of patches with intensity of patch use at Indiana Dunes, we also quantified the percentage of lupine stems with Karner blue larval feeding damage within a patch (Feeding Damage). Fifty lupine stems, separated by at least $1 \mathrm{~m}$ if allowed by patch size, were examined in most patches. In patches containing fewer than 50 stems, we examined all stems and, for patches longer than $100 \mathrm{~m}$, 50 stems per $100 \mathrm{~m}$ of patch length were checked. Feeding Damage was the percentage of stems whose leaves had at least some signs of Karner blue larval feeding damage. Greater Feeding Damage indicated a higher probability that a typical stem within a patch had leaves fed upon by Karner blue larvae during the yearly cycle. In addition to quantifying how much feeding activity occurred in a patch, Feeding Damage is likely related to overall larval success within a patch. For example, Swengel (1995) documented that the number of Karner blue larval feeding signs per plant was positively correlated with number of larvae per plant and that number of adults per site was positively correlated with number of larvae per site.
For each patch, we measured or calculated Patch Area, Slope, Aspect, Heat Load, connectivity $(H)$, Elevation, and Lupine Density or Lupine Cover. Slope, Aspect, and Elevation were determined at the patch centroid by GIS analysis of elevation grids (ESRI, 2005). Heat Load is an index of incident solar radiation derived from the patch's slope, aspect, and latitude (McCune and Keon, 2002, Eq. (2)) and recognizes that steep southwest-facing slopes can reach higher maximum daily temperatures than other combinations of slope and aspect in the Northern Hemisphere. It does not take into account other factors, such as shading from trees or adjacent landforms, which might affect light reaching a patch.

Connectivity $(H)$ of a focal patch $x$ with $n$ surrounding patches (Winfree et al., 2005) was calculated as

$H_{x}=\sum_{i=1}^{n} A_{i} \mathrm{e}^{-d_{i} / D}, \quad i \neq n$

where $A_{i}$ is the area (ha) of surrounding patch $i, d_{i}$ is the distance between patches $x$ and $i$, and $D$ is a mobility constant equal to typical movement distance of the study species. Three variants of $H_{x}$ were calculated. For $H$, all surrounding patches $i$ were used, regardless of their state of occupancy. For $\mathrm{H}_{\text {Occupied, }}$ only occupied surrounding patches were used to calculate $H_{x}$. For $H_{\text {Unoccupied, }}$ only unoccupied surrounding patches were used. We then calculated $H \_$Ratio $=H_{\text {Unoccupied }} /$

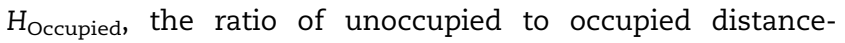
weighted area of lupine patches in the matrix surrounding focal patch $x$. A patch is embedded in a matrix of higher and lower quality habitat for different behaviors of the focal species (Dennis et al., 2006) and H_Ratio is one indicator of the relative amounts of higher and lower quality habitat surrounding a focal patch. Based on average maximum distances between capture locations during mark-release-recapture studies, $D$ was set to $75 \mathrm{~m}$ at Indiana Dunes (Knutson et al., 1999) and $325 \mathrm{~m}$ at Fort McCoy. D for Fort McCoy was based on mark-release-recapture results from Necedah $\mathrm{Na}$ tional Wildlife Refuge (King, 1998), located approximately $40 \mathrm{~km}$ from Fort McCoy, in similar habitat. Necedah results were modified to account for dispersals over large ponds that were present at Necedah but not at Fort McCoy. At Indiana Dunes, areas between networks were mainly devoid of lupine and $H_{x}$ was calculated only using surrounding patches within the network containing patch $x$. Although lupine was uncommon in the area immediately surrounding the perimeter of Fort McCoy, lupine was mapped only to the boundary of the installation and there was a potential effect of lupine outside the Fort's border on $H_{x}$, especially for focal patches near the Fort's boundary. We therefore repeated analyses of the effects of $\mathrm{H}_{x}$ on Patch Occupancy, after limiting surrounding patches for the calculation of $H_{x}$ to those within $325 \mathrm{~m}$ or $650 \mathrm{~m}$ of patch $x$ and eliminating focal patches $x$ within $325 \mathrm{~m}$ and $650 \mathrm{~m}$, respectively, of the Fort's boundary from analysis. This selection ensured that all lupine patches surrounding a given focal patch $x$ were identified. Because results of analyses were similar using $\mathrm{H}_{x}$ calculated at unlimited distances and when restricted to $325 \mathrm{~m}$ or $650 \mathrm{~m}$, we used the unlimited data and did not eliminate patches from the analyses.

At Indiana Dunes, Canopy Cover over patches was measured using a spherical densiometer (Lemmon, 1956). Lupine Cover was the percentage of $1 \mathrm{~m}$-wide $\times 1 \mathrm{~m}$-long segments 
along a patch's longest length and width axes that intersected lupine. At Fort McCoy, Lupine Density was classified as medium or high if lupine clumps within a patch were separated by $<5 \mathrm{~m}$ while low density patches had clumps separated by $>5 \mathrm{~m}$. Tree Density, Timber Cut, and Surrounding Cover were also assessed for each patch at Fort McCoy, based on data derived from a forest inventory completed two years before lupine patch delineation. Timber Cut was the percentage of area within $200 \mathrm{~m}$ of a patch's centroid that had trees removed in the prior 10 years. Patches with open/low Tree Density had $<12 \mathrm{~m}^{2}$ basal area of woody vegetation/ha $(n=727)$. Medium/ high patches had $>12 \mathrm{~m}^{2} /$ ha of small diameter $(<12 \mathrm{~cm} \mathrm{dbh})$ or large diameter $(>12 \mathrm{~cm} \mathrm{dbh})$ woody vegetation $(n=862)$. Surrounding Cover was the percentage of a 200-m wide buffer area surrounding a patch with $>37 \mathrm{~m}^{2} /$ ha of woody vegetation, the highest density category of woody vegetation in the forest inventory. Surrounding Cover is an indicator of whether a patch was surrounded by dense forest habitat that Karner blue adults infrequently inhabit (Schultz, 1998).

\subsection{Statistical analyses}

Linear and logistic regression were used to assess the ability of resource availability (Patch Area, Lupine Density or Lupine Cover), characteristics of the matrix surrounding a focal patch (H, H_Ratio, Surrounding Cover), variables potentially affecting thermal environment of a patch (Canopy Cover, Elevation, Heat Load, Timber Cut, Tree Density), and trend variables (see below) to predict Patch Occupancy or Feeding Damage. Slope, Aspect, $\mathrm{H}_{\text {Occupied }}$, and $\mathrm{H}_{\text {Unoccupied }}$ were incorporated into other predictors (Heat Load, H, and H_Ratio) and were not used as predictors in the regressions. Standard regressions were computed that included all predictors. A parsimonious model representing a tradeoff between model fit and model complexity (Johnson and Omland, 2004) was then computed by the stepAIC procedure ( $\mathrm{R}$ Development Core Team, 2006). stepAIC performs stepwise variable selection that adds or removes predictors to produce a model that minimizes Akaike's Information Criterion (AIC).

Standard or stepwise regressions derive a single, best, predictive equation and provide information on the direction of change in patch use associated with change in a predictor. To assess the ability of each predictor to explain variation in Feeding Damage or Patch Occupancy, hierarchical partitioning of the variation explained by multiple or logistic regression analyses was undertaken (Chevan and Sutherland, 1991; Mac Nally, 2000). Hierarchical partitioning is based on results from all possible regressions involving a set of predictors. For example, given three predictors, $X_{1}, X_{2}$, and $X_{3}$, regressions would be computed using $\left(X_{1}\right),\left(X_{2}\right),\left(X_{3}\right),\left(X_{1}\right.$ and $\left.X_{2}\right),\left(X_{1}\right.$ and $\left.X_{3}\right),\left(X_{2}\right.$ and $\left.X_{3}\right)$, and $\left(X_{1}, X_{2}\right.$, and $\left.X_{3}\right)$ as sets of predictors. The independent effect of each predictor was calculated by computing the average increase in fit for all regressions with a given predictor compared to the equivalent regressions without that predictor (Walsh and Mac Nally, 2005). Fit was measured as $R^{2}$ for multiple regression and reduction in deviance of the fitted model compared to deviance of the null model for logistic regression. The sum of the independent effects of the individual predictors equaled the variation explained by the standard regression model containing all predictors. The significance of the independent effect of a predictor was assessed by randomly reordering each of the predictors within the dataset and computing the independent effects of predictors for each of 200 such randomizations (Mac Nally, 2002). A z-score was calculated as [observed independent effect - mean of independent effect from randomizations]/SD(randomizations). Significance was based on upper confidence limit for $z$. As noted, the predictors evaluated in this study can be grouped to represent the effects of resource availability, surrounding matrix, microclimate, and trend variables. To evaluate the relative importance of these groupings to account for variation in Patch Occupancy or Feeding Damage, the independent effects of the predictors within each grouping were summed.

Trend variables included in regression and hierarchical partitioning analyses were selected from the following logistic regression (for Patch Occupancy as dependent variable) or multiple regression (for Feeding Damage),

$$
\begin{aligned}
& \text { Patch Occupancy (or Feeding Damage) } \\
& \begin{array}{l}
=b_{0}+b_{1} x+b_{2} y+b_{3} x^{2}+b_{4} x y+b_{5} y^{2}+b_{6} x^{3}+b_{7} x^{2} y+b_{8} x y^{2} \\
+b_{9} y^{3}
\end{array}
\end{aligned}
$$

where $x$ is the easting $(m)$ and $y(m)$ is the northing of a patch's centroid, centered on their means and z-score transformed. Significant terms $(p<0.05)$ were retained as trend variables for further analysis along with the other predictors. Northing, Northing ${ }^{2}$, and Northing ${ }^{3}$ were retained for Fort McCoy, Easting ${ }^{2}$ and Northing for Indiana Dunes. Inclusion of trend variables in a regression analysis allows examination of how well position of a patch within a landscape predicts Patch Occupancy or Feeding Damage (Legendre and Legendre, 1998).

Results from the trend analysis were contrasted with results from a spatial autocorrelation analysis. Spatial autocorrelation analysis examined whether Feeding Damage within a focal patch was related to Feeding Damage in neighboring patches, regardless of the focal patch's location within the landscape. Specifically, we calculated a conditional autoregression (CAR) to measure how much variation in Feeding Damage at Indiana Dunes could be explained by spatial autocorrelation between neighboring patches (Kaluzny et al., 1998; Lichstein et al., 2002). For CAR analysis a neighborhood size and neighborhood weight must be defined. The neighborhood size is the maximum distance between patches over which correlation in Feeding Damage between pairs of patches is calculated. We selected $150 \mathrm{~m}$ based on the low frequency of longer movements than this by Karner blues at Indiana Dunes (Knutson et al., 1999). Neighborhood weight is a function describing the relative influence of a neighboring patch on a focal patch. We selected the function $0.943 \mathrm{e}^{-0.0134 d}$, where $d$ is the distance between patch centroids. This function was derived from mark-release-recapture data at Indiana Dunes (Knutson et al., 1999) and $0.943 \mathrm{e}^{-0.0134 d}$ was the probability that an adult butterfly would displace at least a distance $d$ between maximally displaced captures (Baguette, 2003).

Predictors were transformed as needed to improve normality. Transformations applied were: In (Patch Area), fourthroot (H_ratio), arcsin square-root (Indiana Dunes; Lupine Cover, Canopy Cover; Fort McCoy: Surrounding Cover); square-root (Fort 
McCoy: $H$ ). The Box-Cox maximum-likelihood procedure ( $R$ Development Core Team, 2006) was used to determine needed transformation of Feeding Damage in multiple regression analysis and a cube-root transformation was applied. For standard multiple regressions, residuals were examined to ensure that model assumptions were met. Condition indices and variance proportions were examined to ensure that problems with multicollinearity did not occur (SPSS, 2004; Tabachnick and Fidell, 2007). For all regressions, continuous predictor variables were transformed to z-scores to allow more direct comparison of the effects of one predictor to another. Significance of predictors in linear regression was determined by t-test and in logistic regression by the difference in deviance between a model with all predictors entered and a model absent the tested predictor.

\section{Results}

Compared to unoccupied patches ( $n=162)$, occupied patches $(n=1427)$ at Fort McCoy were significantly larger, more northward facing and with a lesser slope, were exposed to more potential incident radiation (higher Heat Load), were at a lower elevation, were more likely to have medium or high lupine density than low lupine density, were surrounded by a relatively low percentage of unoccupied patches (lower H_Ratio), and had lower Surrounding Cover and higher Timber Cut (Table 1). At Indiana Dunes, occupied patches $(n=70)$ were significantly larger and more southward facing than were unoccupied patches $(n=11)$ and had a lower connectivity to surrounding lupine patches (lower $H$ ) (Table 1). Mean area of unoccupied patches was $12 \%$ of mean area of all patches at Indiana Dunes and 30\% at Fort McCoy. In general, predictors were not highly correlated with each other. Excluding trend variables, the highest absolute Pearson correlation at Indiana Dunes between pairs of predictors was -0.36 between Patch Area and Lupine Cover and at Fort McCoy was 0.27 between Elevation and Surrounding Cover.

Regression models containing all predictors accounted for $42.5 \%$ of variation in Feeding Damage at Indiana Dunes $\left(R^{2}\right.$, adj. $=0.351$ ) (Fig. 2a), 62.4\% of variation in Patch Occupancy at Indiana Dunes (explained deviance equaled 40.2 out of total deviance of 64.4 ) (Fig. 2b), and 38.6\% of variation in Patch Occupancy at Fort McCoy (explained deviance equaled 403.8 out of total deviance of 1046.7) (Fig. 2c). All three models containing all predictors were significant at $P<0.001$ (based on $F$-ratio for Feeding Damage and deviance for Patch Occupancy). For Patch Occupancy, these complete models predicted occupancy correctly for $82 \%$ of unoccupied patches and $97 \%$ of occupied patches (for a cutoff probability of 0.5 ) at Indiana Dunes and $41 \%$ of unoccupied patches and $92 \%$ of occupied patches at Fort McCoy.

Independent effects of all predictors were significant at Fort McCoy (Fig. 2c) although the percentages of total explained variation accounted for by most predictors were similar and < 5\%.H_Ratio was the exception with an independent effect of about $10 \%$. The single model selected by stepAIC at Fort McCoy included H_Ratio, Patch Area, Lupine Density, Elevation, Timber Cut, and Northing. The regression coefficients indicated that probability of a patch being occupied increased as Patch Area, Lupine Density, Timber Cut, and Northing increased and as H_Ratio and Elevation decreased.

Independent effects of Patch Area and Northing were significant in explaining variation in Patch Occupancy at Indiana Dunes with Patch Area accounting for nearly $30 \%$ of model

Table 1 - Descriptive statistics (mean \pm SE) for patch characteristics as a function of Patch Occupancy by Karner blue butterflies at Fort McCoy and Indiana Dunes

Patch Occupancy status

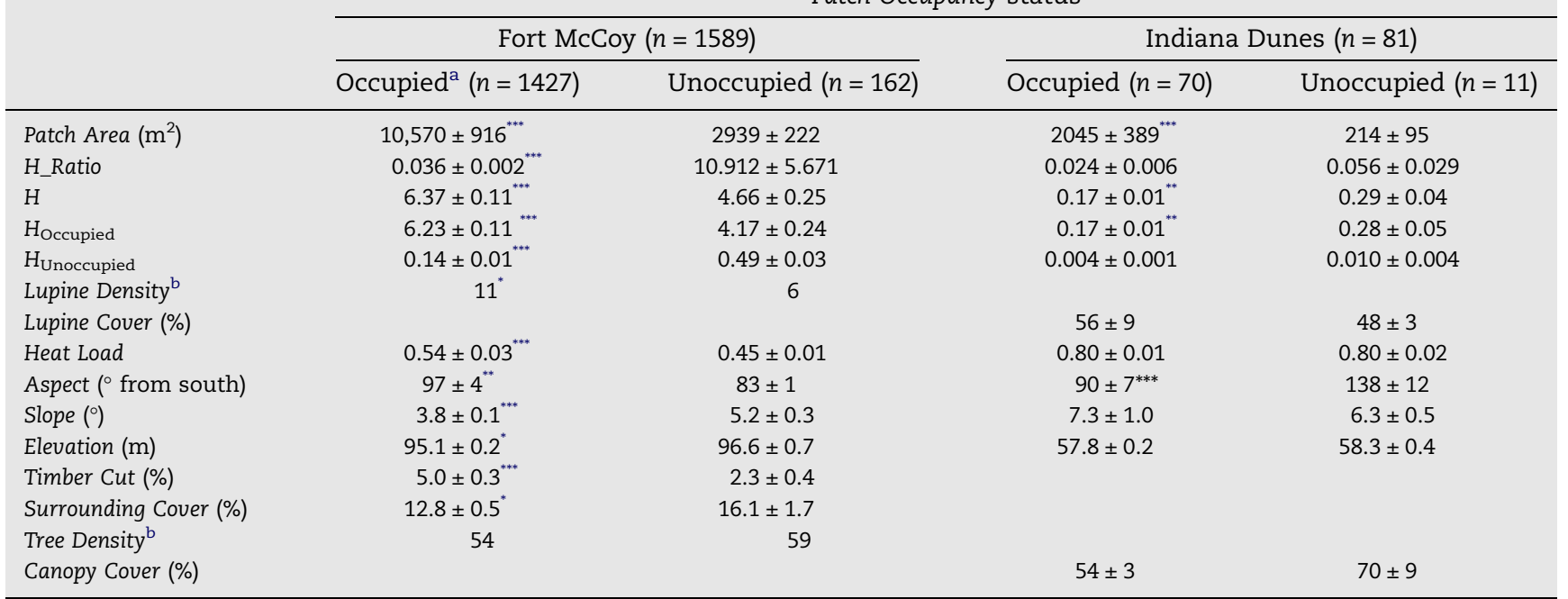

a Probability of Occupied and Unoccupied patches differing from each other at a location (based on $\chi^{2}$ for Lupine Density and Tree Density and t-test for all other variables).

b \% of patches with medium or high Lupine Density or Tree Density.

${ }^{*} p<0.05$.

${ }^{* *} p<0.01$.

*** $p<0.001$. 


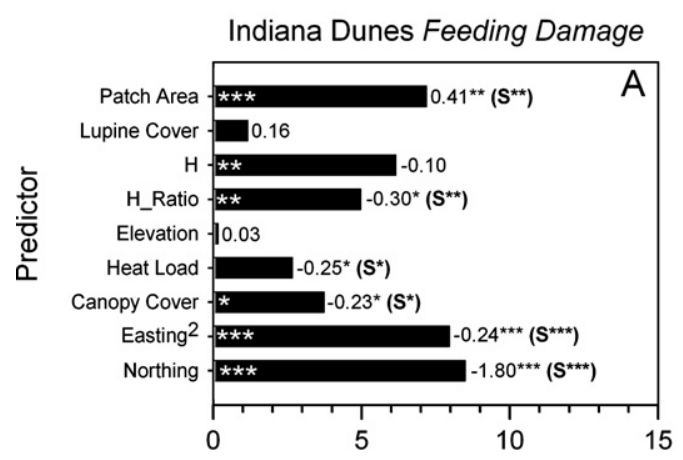

Fort McCoy Patch Occupancy

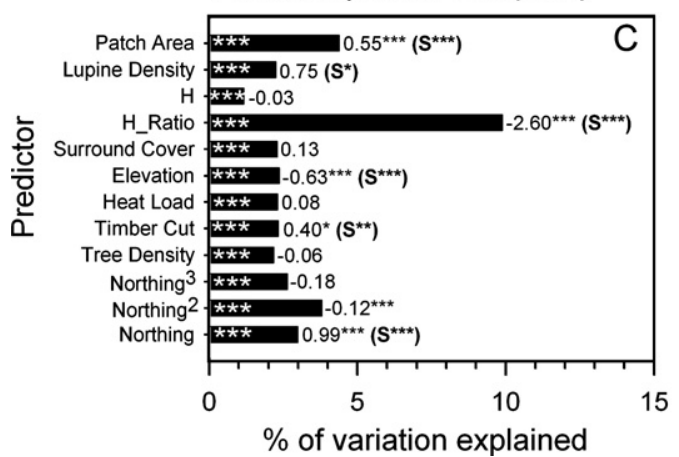

Indiana Dunes Patch Occupancy
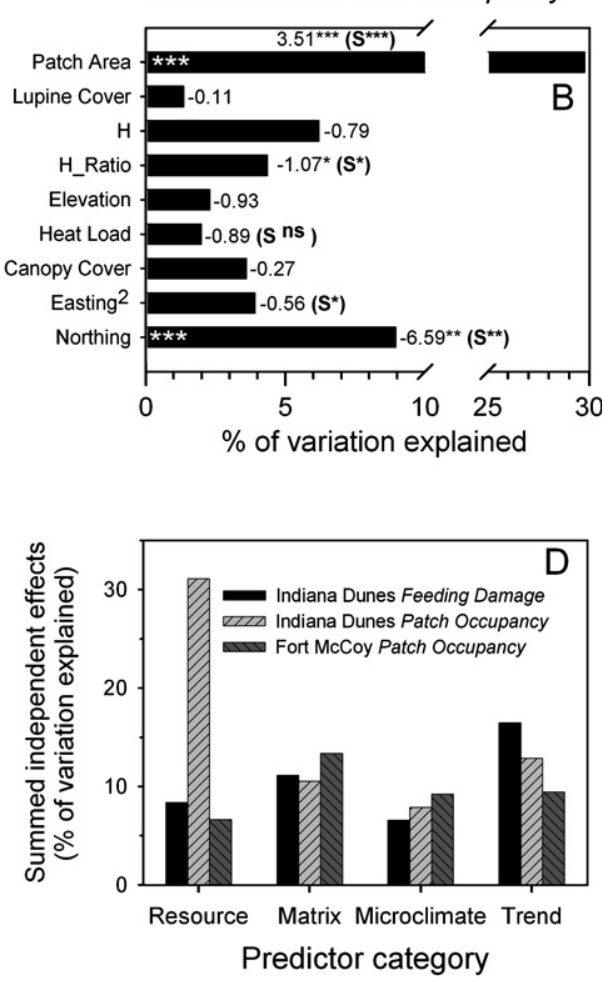

Fig. 2 - Results of standard and stepAIC regression analyses and hierarchical partitioning for the effects of predictors on (A) larval Feeding Damage at Indiana Dunes and Patch Occupancy at (B) Indiana Dunes and (C) Fort McCoy. Bars represent the percentage of variation explained by the independent effects of each predictor, as determined by hierarchical partitioning. Asterisks within bars represent significance of independent effect. Numbers outside of bars represent regression coefficient from standard (A) multiple or (B) and (C) logistic regression. " $S$ " following a coefficient indicates that predictor was selected for inclusion in predictive equation by stepAIC. Significance of independent effects, regression coefficients, and S: ${ }^{*} \mathrm{P}<0.05$, ${ }^{* *} P<0.01,{ }^{* * *} P<0.001,{ }^{n s} P>0.05$. For Fort McCoy, signs of regression coefficients for categorical predictors indicate that increased Lupine Density and decreased Tree Density were associated with increased probability of a patch being occupied. (D) Sum of independent effects by predictor categories resource availability, characteristics of surrounding matrix, factors affecting microclimate, and trend variables.

deviance (Fig. 2b). stepAIC selected Patch Area, both trend variables (Northing and Easting ${ }^{2}$ ), H_Ratio, and Heat Load as predictors of Patch Occupancy, although Heat Load was not statistically significant. Probability of a patch being occupied increased as Patch Area increased and as H_Ratio, Heat Load, Easting $^{2}$, and Northing decreased. This contrasts with importance of predictors for Feeding Damage at Indiana Dunes (Fig. 2a). Independent effects of Patch Area, H_Ratio, H, Canopy Cover, and the two trend variables were significant but the independent effect of Patch Area (6.6\%) was much less than for Patch Occupancy. All significant predictors in the standard multiple regression, Patch Area, H_Ratio, Heat Load, Canopy Couer, and trend variables, were also selected by stepAIC. Feeding Damage increased as Patch Area increased and as H_Ratio, Heat Load, Canopy Cover, and Easting ${ }^{2}$ and Northing decreased.

Resource availability, matrix, and microclimate predictor groups accounted for $7-13 \%$ of variation in patch use (Fig. 2d), with the exception that resource availability accounted for $31 \%$ of variation in Feeding Damage at Indiana Dunes. The trend predictor group accounted for $9-16 \%$ of response variation.

Spatial autocorrelation by itself explained $6.2 \%$ of the variation in Feeding Damage at Indiana Dunes (Table 2). Inclusion of spatial autocorrelation increased $R^{2}$ by 0.033 over a model containing trend and resource availability, matrix, and microclimate predictors but produced almost no change in $R^{2}$ for models containing trend predictors or habitat predictors separately.

\section{Discussion}

Evaluating the relative roles that resource availability, habitat quality, and habitat spatial arrangement have in predicting butterfly distribution can facilitate conservation planning and management for butterflies (Sawchik et al., 2003; Schultz and Crone, 2005; Thomas et al., 2001) and is a major information need identified in the recovery process for the Karner blue butterfly (US Fish and Wildlife Service, 2003). For the Karner blue, host plant availability, variables affecting microclimate, and characteristics of the matrix surrounding a host plant patch each generally accounted for similar percentages of variation (ca. 7-13\%) in butterfly distribution among patches at Indiana Dunes and Fort McCoy, as determined by hierarchical partitioning of variation. Spatial trend, or spatially structured patterns of patch use across the landscape, 
Table 2 - Fit of models predicting Feeding Damage at Indiana Dunes with (R)esource availability, (M)icroclimate, (S)urrounding matrix, (T)rend variables, and Spatial (A)utocorrelation included as predictors

\begin{tabular}{|c|c|c|c|c|c|}
\hline Predictors & $R^{2}$ & $R^{2}, A$ added & Partial $\rho$ & $\rho$ & Significance $\rho$ \\
\hline A & 0.062 & & & 0.35 & 0.02 \\
\hline$R+M+S$ & 0.266 & 0.266 & 0.0002 & 0.04 & 0.89 \\
\hline $\mathrm{T}$ & 0.186 & 0.187 & 0.001 & 0.09 & 0.73 \\
\hline $\mathrm{R}+\mathrm{M}+\mathrm{S}+\mathrm{T}$ & 0.425 & 0.458 & 0.033 & -0.70 & 0.03 \\
\hline
\end{tabular}

Partial $\rho$ is the change in $R^{2}$ associated with the addition of spatial autocorrelation (A). $\rho$ is the spatial autocorrelation parameter. Positive values indicate that higher Feeding Damage within neighboring patches is associated with higher Feeding Damage in the tested patch. Significance $\rho$ indicates whether the model incorporating spatial autocorrelation is significantly better $(P<0.05)$ than the model not incorporating spatial autocorrelation.

accounted for another $9-16 \%$ of distribution variation. At Indiana Dunes, this effect of position within the landscape was stronger than the effect of autocorrelation between neighboring patches in accounting for variation in larval feeding activity among patches.

Did spatial effects outweigh effects of habitat composition in determining patch use by the Karner blue? Assessment of spatial effect is often limited to examining the relationship of patch use to patch connectivity. Indices of patch connectivity, such as $H$ in this study, usually measure resource availability (e.g. lupine abundance) in the matrix surrounding a focal patch and assume that resource availability is an index of potential migrants from the matrix to the focal patch (Winfree et al., 2005). To assess the effect of connectivity, we examined the relationship between $H$ and patch use but additionally calculated a connectivity ratio - connectivity to unoccupied patches: connectivity to occupied patches - and asked whether higher proportions of unoccupied lupine patches in the matrix translated into decreased ability of the focal patch to support Karner blues. Results were consistent with this being true. Probability of patches being occupied and rates of larval feeding damage within a patch both decreased as the connectivity ratio (H_Ratio) increased. H_Ratio accounted for more variation in Patch Occupancy at Fort McCoy than did any other predictor. Such a significant independent effect of $\mathrm{H} \_\mathrm{Ra}$ tio suggests an alternative way of considering patch connectivity that may ally connectivity with, as much as contrast it with, the concept of habitat quality in determining patch use. For example, a high $H \_R a t i o$, such as seen for the matrix surrounding unoccupied patches at Fort McCoy, might indicate a local concentration of poor habitat conditions for patch occupancy that could extend to the focal patch. On the other hand, high H_Ratio could indicate a lack of potential migrants from the surrounding matrix to the focal patch, much as $\mathrm{H}$ is assumed to indicate. If $\mathrm{H}, \mathrm{H} \_$Ratio, Surrounding Cover, spatial trend, and spatial autocorrelation are classified as spatial effects, or effects of environment outside the focal patch on events within the focal patch, then spatial effects explained more variation in Feeding Damage at Indiana Dunes and Patch Occupancy at Fort McCoy, and less variation in Patch Occupancy at Indiana Dunes, than did intrinsic characteristics of the focal patch, such as Patch Area and thermal environment. Thus, the tradeoff between spatial and intrinsic habitat composition effects was dependent on location characteristics, such as the large independent effect of Patch Area on Patch Occupancy at Indiana Dunes, on the metric of patch use (Patch Occupancy versus Feeding Damage), and on which variables might actually be classi- fied as spatial variables and as indicators of habitat quality or quantity.

At both Indiana Dunes and Fort McCoy, larger patches of host plant were associated with positive outcomes from a conservation perspective - higher probability of patches being occupied and greater larval feeding activity. At Indiana Dunes, Patch Area explained more variation in Patch Occupancy (ca. 30\%) than in Feeding Damage (ca. 7\%). This difference illustrates that if minimal resources are available in a patch, the patch may be occupied but other aspects of habitat quality or spatial pattern will have a relatively greater influence on butterfly abundance within the patch (James et al., 2003). Indeed, a greater role for habitat quantity in the determination of occupancy than in the determination of abundance has been noted for other butterfly species (Heikkinen et al., 2005). This shows that differences among studies in the relative importance of habitat composition versus spatial arrangement of habitat in accounting for butterfly distribution may arise, in part, due to different ways of measuring butterfly distribution. Because conservation management will usually attempt to set goals related to population size, understanding factors that affect insect fitness or abundance in patches may more effectively guide management.

Despite the significant relationship between Patch Area and Patch Occupancy at both study sites, the mean cutoff area for patch occupation differed more than 10 -fold between Indiana Dunes $\left(214 \mathrm{~m}^{2}\right.$ mean area for unoccupied patches) and Fort McCoy $\left(2939 \mathrm{~m}^{2}\right)$. Occupied patches at Fort McCoy were also larger than at Indiana Dunes $\left(10,570 \mathrm{~m}^{2}\right.$ versus $\left.2045 \mathrm{~m}^{2}\right)$. Thus, what can be considered a viable patch for butterfly use will likely vary in the context of patch size distributions at a site (Dennis et al., 2006). This precludes the establishment of a rangewide single-area rule for patch size management. The mean area of an unoccupied patch as a percentage of the mean area of all patches also varied considerably between locations (12\% at Indiana Dunes and 30\% at Fort McCoy) again precluding a simple rule-of-thumb for predicting unoccupied patches based on relative size.

Among the variables associated with a patch's microclimate, only Canopy Cover was a significant predictor in both hierarchical partitioning and regression analyses of Feeding Damage at Indiana Dunes. Feeding Damage increased as Canopy Cover decreased, suggesting that patches receiving more solar insolation might experience higher larval feeding rates. However, the relationship of thermal environment to egg laying, larval survivorship, and adult production in the Karner blue is complex and the observed relationship between Feeding 
Damage and Canopy Cover probably only explains part of the relationship between patch use and thermal environment. For example, for Karner blue populations in Minnesota, the fitness advantage of specific thermal environments varied by brood and between years (Lane and Andow, 2003). At Fort McCoy, patches that experienced greater recent removal of trees had a higher probability of being occupied, just as decreased Canopy Cover was associated with greater Feeding Damage at Indiana Dunes. However, Heat Loads at Fort McCoy were lower than at Indiana Dunes and Heat Loads were significantly higher for occupied patches than for unoccupied patches at Fort McCoy but not at Indiana Dunes. These trends suggest that low Heat Loads might limit use of some patches at Fort McCoy. At Fort McCoy, patch elevation also had a significant independent effect on Patch Occupancy. Unoccupied patches there were, on average, $1.5 \mathrm{~m}$ higher in elevation than occupied patches, placing lupines in unoccupied patches considerably higher above the water table. Because both study sites have well-drained sandy soils, higher patch elevation can increase the likelihood of water stress in, and early senescence of, lupines. Lupine water stress and senescence are factors known to increase larval development time (Grundel et al., 1998a), especially as larvae of the second brood search for food in mid-summer as lupine begins to senesce.

Thermal environment also may have contributed to spatial trend patterns in patch use observed at Indiana Dunes. Feeding Damage and Patch Occupancy were lower in the northern part of the study area. Given the east-west orientation of dunes at Indiana Dunes, more northerly patches are more likely to reside on northern dune aspects, which do not directly face the sun and typically have sparse lupine. Spatial trend represented broad-scale spatial effect (Kaluzny et al., 1998; Lichstein et al., 2002) in that it examined whether Feeding Damage or Patch Occupancy varied systematically in space across a landscape. This contrasts with spatial autocorrelation, which examined relationships between neighboring patches, regardless of their location within a landscape. Compared to the variation explained by spatial trend variables only (18.6\%), spatial autocorrelation explained little additional variation $(0.1 \%)$ in Feeding Damage at Indiana Dunes. The amount of variation explained by spatial autocorrelation by itself (6.2\%) was also much less than explained only by spatial trend. Therefore, comparatively, the ability of larval feeding activity in one patch to predict feeding activity in a neighboring patch within $150 \mathrm{~m}$ was substantially less than the ability of broader scale characteristics of the landscape, such as topographic position, to explain feeding variability.

\subsection{Conservation implications}

Basing management decisions on factors affecting patch occupancy versus factors affecting intensity of patch use can lead to different prioritizations for landscape management. Making decisions that are more strongly tied to insect demography should be preferred. Thus, for example, at Indiana Dunes understanding predictors of Feeding Damage might provide better management guidance than understanding predictors of Patch Occupancy, assuming that trends in Feeding Damage reflect trends in larval success, as has been suggested for Karner blue larvae in Wisconsin (Swengel, 1995). Even more direct mea- surement of demographic parameters, such as done by Lane and Andow (2003), and relating those parameters to resource, matrix, microclimate, and spatial predictors across the Karner blue's range would likely further improve the usefulness of research findings to species management. The results here suggested that resource availability, quality of the surrounding matrix, and factors affecting microclimate each had a similar, significant but modest ability to explain variation in patch use. Therefore, resource managers must manage the thermal environment as well as manage abundance of the larval host plant. In a monophagous species like the Karner blue, it is easy to focus on abundance of host plant as the prime determinant of insect population success but that is an incomplete approach to management. Indeed, the quality of the surrounding matrix, expressed as connectivity to surrounding patches and the likelihood that those patches will be occupied, often had a slightly larger independent effect in accounting for variability in patch occupancy than did host plant abundance or microclimate in the focal patch. Finally, the relatively large independent effect of spatial trend suggests that even though host plant patches might occur in many parts of the landscape, not all parts of the landscape were equivalent as background for a lupine patch in which Karner blues would successfully oviposit and develop to adults. The variability accounted for by spatial trend variables likely represents spatial patterning of unmeasured determinants of patch use. Documenting those spatial trends and using those patterns to discover new determinants of successful patch use can further guide successful management. This documentation can also help managers avoid undertaking habitat modifications that are less likely to improve Karner blue fitness due to underlying constraints, such as unfavorable topographic position of patches.

\section{Acknowledgements}

Data from Fort McCoy were collected and compiled by Department of the Army personnel and contractors. We especially thank Tim Wilder, Dave Aslesen, and Chad Kuhn who helped us greatly in the acquisition and interpretation of those data and we gratefully acknowledge their willingness to share these data. We thank Randy Knutson for leading the mark-release-recapture studies cited here and the National Park Service for permission to work at Indiana Dunes National Lakeshore. We thank Tom Lavelle, Chris Sulzman and Shelley Swisher for their help with data collection at Indiana Dunes and Stacey Young and two anonymous reviewers for constructive comments on the manuscript. Work was authorized by an endangered species permit from the US Fish and Wildlife Service. We thank the US Geological Survey and the US Environmental Protection Agency for funding this work. This article is Contribution 1392 of the USGS Great Lakes Science Center.

\section{R E F E R E N C E S}

Anthes, N., Fartmann, T., Hermann, G., Kaule, G., 2003. Combining larval habitat quality and metapopulation structure - the key for successful management of pre-alpine Euphydryas aurinia colonies. Journal of Insect Conservation 7, 175-185. 
Baguette, M., 2003. Long distance dispersal and landscape occupancy in a metapopulation of the cranberry fritillary butterfly. Ecography 26, 153-160.

Baguette, M., Schtickzelle, N., 2006. Negative relationship between dispersal distance and demography in butterfly metapopulations. Ecology 87, 648-654.

Chevan, A., Sutherland, M., 1991. Hierarchical partitioning. The American Statistician 45, 90-96.

Cowles, H.C., 1899. Ecological relations of the vegetation on sand dunes of Lake Michigan. Botanical Gazette 27, 95-117, 167-202, 281-308, 361-391.

Dennis, R.L.H., Eales, H.T., 1997. Patch occupancy in Coenonympha tullia (Muller, 1764) (Lepidoptera: Satyrinae): habitat quality matters as much as patch size and isolation. Journal of Insect Conservation 1, 167-176.

Dennis, R.L.H., Sparks, T.H., 2006. When is a habitat not a habitat? Dramatic resource use changes under differing weather conditions for the butterfly Plebejus argus. Biological Conservation 129, 291-301.

Dennis, R., Shreeve, T., Van Dyck, H., 2006. Habitats and resources: the need for a resource-based definition to conserve butterflies. Biodiversity and Conservation 15, 1943-1966.

Doak, P., 2000. Population consequences of restricted dispersal for an insect herbivore in a subdivided habitat. Ecology 81, 18281841.

ESRI, 2005. ArcMap Version 9.0. Environmental Systems Research Institute, Redlands, CA, USA.

Fleishman, E., Launer, A.E., Weiss, S.B., Reed, J.M., Boggs, C.L., Murphy, D.D., Ehrlich, P.R., 2000. Effects of microclimate and oviposition timing on prediapause larval survival of the Bay checkerspot butterfly, Euphydryas editha bayensis (Lepidoptera: Nymphalidae). Journal of Research on the Lepidoptera 36, 4144.

Fleishman, E., Ray, C., Sjögren-Gulve, P., Boggs, C.L., Murphy, D.D., 2002. Assessing the roles of patch quality, area, and isolation in predicting metapopulation dynamics. Conservation Biology 16, 706-716.

Fred, M.S., O'Hara, R.B., Brommer, J.E., 2006. Consequences of the spatial configuration of resources for the distribution and dynamics of the endangered Parnassius apollo butterfly. Biological Conservation 130, 183-192.

Gripenberg, S., Roslin, T., 2005. Host plants as islands: resource quality and spatial setting as determinants of insect distribution. Annales Zoologici Fennici 42, 335-345.

Grundel, R., Pavlovic, N.B., Sulzman, C.L., 1998a. The effect of canopy cover and seasonal change on host plant quality for the endangered Karner blue butterfly (Lycaeides melissa samuelis). Oecologia 114, 243-250.

Grundel, R., Pavlovic, N.B., Sulzman, C.L., 1998b. Habitat use by the endangered Karner blue butterfly in oak woodlands: the influence of canopy cover. Biological Conservation 85, 47-53.

Gutiérrez, D., Thomas, C.D., Leon-Cortes, J.L., 1999. Dispersal, distribution, patch network and metapopulation dynamics of the dingy skipper butterfly (Erynnis tages). Oecologia 121, 506517.

Hanski, I., Meyke, E., 2005. Large-scale dynamics of the Glanville fritillary butterfly: landscape structure, population processes, and weather. Annales Zoologici Fennici 42, 379-396.

Hanski, I., Moilanen, A., Pakkala, T., Kuussaari, M., 1996. The quantitative incidence function model and persistence of an endangered butterfly metapopulation. Conservation Biology $10,578-590$.

Harrison, S., Murphy, D.D., Ehrlich, P.R., 1988. Distribution of the Bay checkerspot butterfly, Euphydryas editha bayensis: evidence for a metapopulation model. American Naturalist 132, 360382.

Heikkinen, R.K., Luoto, M., Kuussaari, M., Pöyry, J., 2005. New insights into butterfly-environment relationships using partitioning methods. Proceedings of the Royal Society of London B 272, 2203-2210.

Hellmann, J.J., 2002. The effect of an environmental change on mobile butterfly larvae and the nutritional quality of their hosts. Journal of Animal Ecology 71, 925-936.

James, M., Gilbert, F., Zalat, S., 2003. Thyme and isolation for the Sinai baton blue butterfly (Pseudophilotes sinaicus). Oecologia 134, 445-453.

Johnson, J.B., Omland, K.S., 2004. Model selection in ecology and evolution. Trends in Ecology and Evolution 19, 101-108.

Kaluzny, S.P., Vega, S.C., Cardoso, T.P., Shelly, A.A., 1998. S+ SpatialStats: User's Manual for Windows and Unix. SpringerVerlag, New York.

King, R.S., 1998. Dispersal of Karner blue butterflies (Lycaeides melissa samuelis) at Necedah National Wildlife Refuge. Transactions of the Wisconsin Academy of Sciences, Arts and Letters 86, 101-110.

Knutson, R.L., Kwilosz, J.R., Grundel, R., 1999. Movement patterns and population characteristics of the Karner blue butterfly (Lycaeides melissa samuelis) at Indiana Dunes National Lakeshore. Natural Areas Journal 19, 109-120.

Krauss, J., Steffan-Dewenter, I., Tscharntke, T., 2004. Landscape occupancy and local population size depends on host plant distribution in the butterfly Cupido minimus. Biological Conservation 120, 355-361.

Lane, C.P., Andow, D.A., 2003. Oak savanna subhabitat variation and the population biology of Lycaeides melissa samuelis (Lepidoptera: Lycaenidae). Annals of the Entomological Society of America 96, 799-809.

Legendre, P., Legendre, L., 1998. Numerical Ecology, second ed. Elsevier, Amsterdam, The Netherlands.

Lemmon, P.E., 1956. A spherical densiometer for estimating forest overstory density. Forest Science 2, 314-320.

Lichstein, J.W., Simons, T.R., Shriner, S.A., Franzreb, K.E., 2002. Spatial autocorrelation and autoregressive models in ecology. Ecological Monographs 72, 445-463.

Mac Nally, R., 2000. Regression and model-building in conservation biology, biogeography and ecology: the distinction between - and reconciliation of - 'predictive' and 'explanatory' models. Biodiversity and Conservation 9, 655671.

Mac Nally, R., 2002. Multiple regression and inference in ecology and conservation biology: further comments on identifying important predictor variables. Biodiversity and Conservation 11, 1397-1401.

McCune, B., Keon, D., 2002. Equations for potential annual direct incident radiation and heat load. Journal of Vegetation Science 13, 603-606.

Moilanen, A., Hanski, I., 1998. Metapopulation dynamics: effects of habitat quality and landscape structure. Ecology 79, 25032515.

Moilanen, A., Nieminen, M., 2002. Simple connectivity measures in spatial ecology. Ecology 83, 1131-1145.

R Development Core Team, 2006. R: A language and environment for statistical computing, version 2.3.1. R Foundation for Statistical Computing, Vienna, Austria.

Sawchik, J., Dufrêne, M., Lebrun, P., 2003. Estimation of habitat quality based on plant community, and effects of isolation in a network of butterfly habitat patches. Acta Oecologica 24, 2533.

Schultz, C.B., 1998. Dispersal behavior and its implications for reserve design in a rare Oregon butterfly. Conservation Biology 12, 284-292.

Schultz, C.B., Crone, E.E., 2005. Patch size and connectivity thresholds for butterfly habitat restoration. Conservation Biology 19, 887-896.

Smith, M.A., Turner, M.G., Rusch, D.H., 2002. The effect of military training activity on eastern lupine and the Karner blue 
butterfly at Fort McCoy, Wisconsin, USA. Environmental Management 29, 102-115.

SPSS, Inc., 2004. SPSS Release 12.0.2, Chicago.

Swengel, A.B., 1995. Observations of spring larvae of Lycaeides melissa samuelis (Lepidoptera: Lycaenidae) in central Wisconsin. Great Lakes Entomologist 28, 155-170.

Tabachnick, B.G., Fidell, L.S., 2007. Using Multivariate Statistics. fifth ed., Allyn and Bacon, Boston.

Thomas, J.A., Bourn, N.A.D., Clarke, R.T., Stewart, K.E., Simcox, D.J., Pearman, G.S., Curtis, R., Goodger, B., 2001. The quality and isolation of habitat patches both determine where butterflies persist in fragmented landscapes. Proceedings of the Royal Society of London B 268, 1791-1796.
US Fish and Wildlife Service, 2003. Final Recovery Plan for the Karner Blue Butterfly (Lycaeides melissa samuelis). US Fish and Wildlife Service, Fort Snelling, Minnesota.

van Nouhuys, S., 2005. Effects of habitat fragmentation at different trophic levels in insect communities. Annales Zoologici Fennici 42, 443-447.

Walsh, C., Mac Nally, R., 2005. hier.part: Hierarchical Partitioning. $\mathrm{R}$ package version 1.0-1.

Weiss, S.B., Murphy, D.D., White, R.R., 1988. Sun, slope, and butterflies: topographic determinants of habitat quality for Euphydryas editha. Ecology 69, 1486-1496.

Winfree, R., Dushoff, J., Crone, E.E., Schultz, C.B., Budny, R.V., Williams, N.M., Kremen, C., 2005. Testing simple indices of habitat proximity. American Naturalist 165, 707-717. 